\title{
Conceptual modelling to assess how the interplay of hydrological connectivity, catchment storage and tracer dynamics controls non-stationary water age estimates
}

\begin{tabular}{|r|l|}
\hline Journal: & Hydrological Processes \\
\hline Manuscript ID: & HYP-14-0391.R2 \\
\hline Wiley - Manuscript type: & Research Article \\
\hline Date Submitted by the Author: & 22-Nov-2014 \\
\hline Complete List of Authors: & $\begin{array}{l}\text { Birkel, Christian; University Aberdeen, Northern Rivers Institute } \\
\text { Soulsby, Chris; University Aberdeen, Northern Rivers Institute } \\
\text { Tetzlaff, Doerthe; University Aberdeen, Northern Rivers Institute }\end{array}$ \\
\hline Keywords: & $\begin{array}{l}\text { Catchment storage, water age, rainfall-runoff model, tracers, connectivity, } \\
\text { stable isotopes }\end{array}$ \\
\hline
\end{tabular}

SCHOLARONE ${ }^{m}$

Manuscripts 
1 Conceptual modelling to assess how the interplay of hydrological connectivity, catchment storage and tracer dynamics controls non-stationary water age estimates

$4 \quad$ Christian Birkel $^{1}$, Chris Soulsby ${ }^{1}$, Doerthe Tetzlaff ${ }^{1}$

$5{ }^{1}$ Northern Rivers Institute, School of Geosciences, University of Aberdeen, Aberdeen, UK.

6 Correspondence to: c.birkel@abdn.ac.uk

7

8 Abstract

9 Although catchment storage is an intrinsic control on the rainfall-runoff response of 10 streams, direct measurement remains a major challenge. Coupled models that integrate 11 long-term hydrometric and isotope tracer data are useful tools that can provide insights into 12 the dynamics of catchment storage and the volumes of water involved. In this study, we use 13 a tracer-aided hydrological model to characterize catchment storage as a dynamic control 14 on system function related to streamflow generation, which also allows direct estimation of 15 the non-stationarity of water ages. We show that in a wet Scottish upland catchment 16 dominated by runoff generation from riparian peats (histosols) with high water storage, 17 non-stationarity in water age distributions are only clearly detectable during more extreme 18 wet and dry periods. This is explained by the frequency and longevity of hydrological 19 connectivity and the associated relative importance of flow paths contributing younger or 20 older waters to the stream. Generally, these saturated riparian soils represent large mixing 21 zones that buffer the time variance of water age and integrate catchment-scale partial 22 mixing processes. Although storage simulations depend on model performance, which is 
23 influenced by input variability and the degree of isotopic damping in the stream, a longer-

24 term storage analysis of this model indicates a system which is only sensitive to more 25 extreme hydroclimatic variability.

27 Keywords: Catchment storage, water age, rainfall-runoff model, tracers, stable isotopes, 28 connectivity.

\section{I Introduction}

31 The relationship between catchment water storage and discharge is fundamental to 32 understanding the hydrological response of streams (Kirchner, 2009). Recent years have 33 seen many studies attempting to characterize catchment storage dynamics. These include 34 for example direct hydrometric analysis (McNamara et al., 2011; Brauer et al., 2013), use of 35 conservative tracers (Soulsby et al., 2009), application of hydrological models (Birkel et al., 36 2011a), new field instrumentation (e.g. COSMOS - Zreda et al., 2012) and remote sensing 37 (e.g. GRACE - Rodell et al., 2009). These alternative approaches have yielded different 38 insights often relevant at contrasting spatial scales. However, given the difficulties in fully 39 characterizing subsurface hydrology (e.g. soil moisture and groundwater variability) at the 40 catchment scale, in most cases, only a partial view of storage dynamics are given by the 41 different methods. For example, hydrometric analysis provides insight into the near-surface 42 storage dynamics that reflect water balance processes (Kirchner, 2009). However, models 43 that concurrently track conservative tracers between rainfall and runoff usually infer much 44 larger volumes of storage, needed to damp and lag tracer input variability in outputs (Birkel 
45 et al, 2011a). These large storage volumes were first proposed in the form of additional 46 parameters in conceptual models reflecting storage volumes that participate with solute 47 mixing but do not affect streamflow dynamics (Barnes and Bonell, 1996). Even detailed soil 48 moisture and groundwater monitoring at the hillslope scale can miss important dynamics in 49 the weathering zone (Salve et al., 2012). Only in extensively studied small experimental 50 watersheds - usually with a well-characterized, shallow subsurface - can constrained, 51 quantitative estimates of total catchment storage be achieved (e.g. Bishop et al., 2011; 52 Peters et al., 2013). Investigating both short-term (e.g. hourly and daily) and longer-term (e.g. intra- and interannual) storage change is crucial to understanding non-stationarity in catchment hydrological function and stream flow behaviour (e.g. Brooks et al., 2009; Rinaldo et al.,

57 2011). Conservative tracers can play an important role in this regard and integrating tracers in rainfall-runoff models shows promise as learning tools in hypothesis testing (Soulsby et al., 2008). Such integration has helped to elucidate the inter-relationships between the short-term storage dynamics that reflect the catchment water balance and stream flow response with the mixing processes that regulate solute transport and control water transit times (e.g. Fenicia et al., 2010; Heidbüchel et al., 2012). However, the potential of such models to explore non-stationarity in mixing processes and resulting time-variant water age distributions has only recently started to be explored (McMillan et al., 2012; Hrachowitz et al., 2013). Theoretical work by Rinaldo et al. (2011) and Botter et al. (2011) emphasized the differences between the age of water in transit and in storage, which under non-steady conditions can not be assumed identical. In this context, integrated flow-tracer models have 
68 particular potential to better understand catchment functioning (McDonnell and Beven,

69 2014) in catchments where long-term hydrometric data is complemented by time series of

70 tracer data from the major runoff source areas where mixing occurs (e.g. soil water,

71 groundwater etc.). This allows direct testing of hypotheses about mixing and water age in

72 different storage components (Birkel et al., 2014).

74 In this study, we build on a previous model of the Girnock catchment (Birkel et al., 2010) by

75 examining long term hydrometric data (> 40 years), tracer data (> 10 years), and ancillary

76 process-based data on soil hydrology and groundwater dynamics (Tetzlaff et al., 2014). The

77 site is also more broadly representative of other northern upland catchments facilitating

78 transferability. Tracer-aided models have been developed here which allow catchment

79 storage in different landscape units to be estimated (Birkel et al., 2011b). However, the

80 literature is marked by inconsistency in the terminology used to describe different elements

81 of catchment storage; with terms like active, dynamic, hydraulic, passive, residual, immobile

82 and dead storage, used amongst other. For clarity in our model, we define catchment

83 storage as the sum of dynamic storage and additional storage available for mixing that can

84 be detected using hydrometric and conservative tracer data. This acknowledges that the

85 total catchment storage is difficult - usually impossible - to determine. In this paper we

86 define storage that actively or hydraulically contributes to discharge as dynamic storage.

87 The storage that does not necessarily contribute to discharge but is available for mixing

88 tracer inputs is subsequently termed the additional storage mixing volume.

89 We use a unique six year data set of weekly and event-targeted daily oxygen-18 isotopes of

90 precipitation and streamflow from the Girnock catchment. These years from 2003 to 2009 
91 incorporate periods of marked hydrological contrasts including the latter part of the Europe-

92 wide drought in 2003 and a very wet year in 2006/07. The tracer data was integrated into a

93 low-parameter conceptual model to simulate stream flow on the basis of dynamic storage

94 changes, as well as exploring how hydroclimatic variability results in differences in the

95 proportion of additional storage volumes mobilized for mixing. The variability of mobilized

96 additional storage volumes is hypothesized as the main driver of non-stationary water ages.

97 Our specific objectives to assess the latter are firstly to explore long-term internal storage

98 dynamics using a multi-objective, moving window calibration of a parsimonious, rainfall-

99 runoff model coupled with an isotope transport model to simulate daily discharge and

100 oxygen-18 dynamics. Secondly, we investigate how the different calibration windows of

101 dynamic storage and additional storage mixing volumes relate to hydroclimatic variability,

102 catchment connectivity and flow paths, model performance, the information content of

103 tracer data and resulting stream water age estimates.

105 II Study catchment

106 The Girnock Burn is located in the Cairngorm Mountains of Scotland and drains about 30

$107 \mathrm{~km}^{2}\left(57^{\circ} 00^{\prime} 59^{\prime \prime}\right.$ North and $3^{\circ} 07^{\prime} 60^{\prime \prime}$ West, Figure 1). Its catchment characteristics are

108 detailed elsewhere (Soulsby et al., 2007; Tetzlaff et al., 2007). Briefly, average annual

109 precipitation over the study period from 2000 to 2009 is around $950 \mathrm{~mm}$, with annual runoff

110 of $530 \mathrm{~mm}$ and potential evapotranspiration of $408 \mathrm{~mm}$. These figures are close to the long-

111 term averages since 1970 . The altitudinal range is $631 \mathrm{~m}$ with a maximum at $861 \mathrm{~m}$. Granitic

112 rocks can mostly be found at higher-elevation areas while schists predominate at lower

113 elevations (Soulsby et al., 2007). These rocks have generally poor aquifer characteristics, 
114 and due to the glacial legacy much of the catchment is covered by low-permeability drift

115 deposits (in parts $>30 \mathrm{~m}$ deep). In the valley bottoms histosols (peats and peaty gleys)

116 fringe much of the stream channel network. These riparian soils remain close to saturation

117 all year round and generate saturation overland flow as storm runoff (Ali et al., 2014). They

118 receive input from upslope freely draining podzolic soils (which also facilitate deeper

119 groundwater recharge) in the form of quasi-continuous groundwater seepage and

120 threshold-like non-linear near-surface connections from lateral flow during larger storm

121 events (Tetzlaff et al., 2014). These connectivity dynamics cause the saturation zone to

122 expand and contract (its observed spatial extent varies between $2-40 \%$ of the catchment

123 area) and drive the catchment hydrological response (Birkel et al., 2010). Snow usually melts

124 quickly (within a matter of days over most of the catchment) and generally comprises of $<5$

$125 \%$ of the annual water balance (Capell et al., 2013).

126

127

128 III Data and Methods

$129 \quad 3.1$ Hydrometric and isotopic data

130 Daily discharge $(Q)$ data was derived from recorded water levels at Littlemill (Scottish

131 Environment Protection Agency, SEPA). Precipitation $(P)$ was interpolated using a squared

132 elevation inverse distance weighted algorithm similar to Birkel et al. (2011a) based on 12

133 SEPA rain gauges located around the Girnock catchment. Potential evapotranspiration (PET)

134 was estimated using Penman-Monteith from an automatic weather station within the

135 Girnock (Marine Scotland Science) for the dominant heather moorland vegetation and then 
136 adjusted prior to modelling using an annual scaling coefficient $K E T$ to match the water

137 balance. This resulted in modifications between $0.94<\mathrm{kET}<1.09$.

138

Water samples (accumulated rain and instantaneous stream spot samples) were analyzed

140 for oxygen-18 isotopes in \%o. Samples were collected at approximately weekly intervals but

141 where possible, attempts were also made to capture the peaks of storm events between

142 October 2003 and September 2009. Isotope analysis was conducted using gas source

143 isotope mass spectroscopy (precision: $\pm 0.1 \%$ ) at the Scottish Universities Environmental

144 Research Centre and the James Hutton Institute.

$146 \quad 3.2$ Model approach

147 Previous work has reported a suite of rainfall-runoff models developed for the Girnock using

148 tracers to help constrain the model structure. These models simulated stream flow based on

149 the dominant geographic sources of runoff (Tetzlaff et al., 2008; Birkel et al., 2010) and their

150 temporal dynamics (Birkel et al., 2011a, b; Birkel et al., 2014). The non-linearities of the

151 runoff response were successfully incorporated in a tracer-conditioned dynamic saturation

152 area model (full details given in Birkel et al., 2010). This latter model is based on a dynamic

153 conceptualization of hydrological connectivity associated with quick near-surface runoff

154 generation mechanisms in saturation areas, together with a linked groundwater store (to

155 see Figure 2 for the model structure, connections between stores, and basic equations). The

156 connectivity of the saturation area to the stream was estimated as a function of antecedent

157 wetness and soil moisture capacity. A 7-day antecedent wetness algorithm was calibrated 
158 against seven actual saturation area maps (derived from field observation) to best represent

159 the dynamic expansion and contraction of the saturation area (details in Birkel et al., 2010;

160 also see Ali et al., 2014). This allowed a daily time series of \% catchment saturation area

161 (dSAT) to be used directly as model input to volumetrically differentiate the hillslope

162 reservoir from the saturation area store. Subsequently, catchment precipitation $P$ and

163 potential evapotranspiration $E T$ are distributed into hillslope $\left(P_{u p}, E T_{\text {up }}\right)$ and saturation area

$164\left(P_{\text {sat }}, E T_{\text {sat }}\right)$ according to the extent of $d S A T$ (only the equations for precipitation are given for 165 illustration):

166

$167 P_{u p}=P d S A T$

$168 P_{\text {sat }}=1-P_{u p}$

170 Here, the original model of Birkel et al. (2010) was modified to conceptualize unsaturated 171 storage units (Figure 2); in other words reservoirs do not have a lower limit and levels below

172 a pre-defined baseline prevents generation of lateral and vertical fluxes except 173 evapotranspiration. The unsaturated storage was conceptualized to reflect soil moisture174 related threshold processes of runoff generation (Tetzlaff et al., 2014). The storages $S$ are 175 model state variables and we describe the following fluxes and calibrated parameters. The 176 unsaturated hillslope reservoir $S_{u p}$ is drained (flux $Q_{1}$ in $\mathrm{mm} \mathrm{d}^{-1}$ ) by the linear rate 177 parameter $a\left(d^{-1}\right)$ and directly contributes to the saturation area store $S_{\text {sat; }}$ the recharge rate $178 R\left(\mathrm{~mm} \mathrm{~d}^{-1}\right)$ to the groundwater reservoir $S_{\text {low }}$ is linearly calculated using the parameter $\operatorname{Re}\left(\mathrm{d}^{-}\right.$ $\left.179{ }^{1}\right)$; the $S_{\text {low }}$ generates runoff $Q_{\text {low }}\left(\mathrm{mm} \mathrm{d}^{-1}\right)$ contributing to total streamflow $Q\left(\mathrm{~mm} \mathrm{~d}^{-1}\right)$ using 
180 the linear rate parameter $b\left(\mathrm{~d}^{-1}\right)$. The runoff component $Q_{\text {sat }}$ (in $\mathrm{mm} \mathrm{d}^{-1}$ ) generated 181 nonlinearly from $S_{\text {sat }}$ conceptualizes saturation overland flow using the rate parameter $k\left(\mathrm{~d}^{-}\right.$ $182{ }^{1}$ ) and the nonlinearity parameter $\alpha(-)$ in a power function-type equation (Figure 2); and $Q$ is 183 simply the sum of $Q_{\text {sat }}$ and $Q_{\text {low. }}$. Each of the three reservoirs $\left(S_{\text {up }}, S_{\text {sat }}\right.$ and $S_{\text {low }}$ in $\mathrm{mm}$ ) 184 incorporates an additional calibrated storage parameter $\left(u p S_{p}\right.$, sat $S_{p}$ and low $S_{p}$, respectively 185 in $\mathrm{mm}$ ) for isotope transport simulations. This was achieved by creating an additional 186 volume available for isotope storage, mixing and transport that does not affect the dynamic 187 water storage and fluxes:

$189 \frac{d(c S)}{d t}=\sum_{j} c_{I, j} I_{j}-\sum_{k} c_{O, k} O_{k}$

With $c$ being the $\delta^{18} \mathrm{O}$ signature of storage components (\%o) in $j$ storage inflows $l_{j}$ (e.g. $P$, $\left.Q_{u p}, R\right)$ and $k$ outflow $O_{k}$ components (e.g. $E T, Q_{\text {low }}, Q_{\text {sat }}$ ), which characterizes the catchment storage $S$ dynamics (sum of dynamic and additional storage available for mixing) and associated isotope signature $c$. Dynamic storage $\left(S_{d}\right)$ was calculated as the sum of the three internal model storage units $\left(S_{u p}, S_{\text {sat }}\right.$ and $\left.S_{\text {low }}\right)$. However, the additional storage parameters were subsequently converted into time-variable mixing volumes $(M V)$. This was done with the premise of using the non-linear rainfall-runoff model as a means of relaxing the assumption of complete mixing at the catchment scale without introducing new parameters. Thus, as the rainfall-runoff model dynamically varies the extent of the $S_{\text {sat }}$ and $S_{u p}$, the complete mixing in individual reservoirs is integrated at the catchment scale in a non-linear manner. The $M V s$ therefore represent a partial mixing mechanism and were 
202 calculated according to the catchment wetness (dSAT) state assuming that greater wetness 203 results in greater saturation area extent but also greater potential for mixing $\left(M V_{\text {sat }}\right)$. In 204 contrast, it is assumed that the hillslope mixing volume $\left(M V_{u p}\right)$ decreased as the saturation 205 area expands. This is consistent with the hydrological model and the key goal of a minimal 206 number of model parameters:

207

$208 M V_{s a t}=$ satS $_{p} d S A T$

$209 M V_{u p}=u p S_{p}(1-d S A T)$

211 Since $S_{d}$ actively contributes to discharge (Figure 2), we excluded situations when storages 212 below the baseline did not generate outflow. Catchment storage $(S)$ estimates (identifiable 213 from hydrometric and isotopic data) use the three mixing volumes $\left(S_{M V}\right)$ in addition to the $214 S_{d}$. The simple $S$ to $Q$ ratio (total streamflow) is used as the mean annual transit time 215 estimate (TT) in an attempt to assess inter-annual dynamics and possible non-stationary 216 behaviour (Zuber, 1986; Soulsby et al., 2009):

$218 T T=\frac{S_{d}+S_{M V}}{Q}$

220 Recognizing that exponential models resulting from a linear, well-mixed reservoir 221 (Maloszewski and Zuber, 1982) are usually inadequate in fully describing tracer dynamics 
222 (Kirchner et al., 2000), this model effectively integrates three reservoirs. One reservoir is 223 non-linear $\left(S_{\text {Sat }}\right)$, two reservoirs incorporate partial mixing mechanisms $\left(S_{\text {Sat }}\right.$ and $\left.S_{\text {up }}\right)$ and 224 transport to the stream is calculated by two parallel reservoirs $\left(S_{\text {Sat }}\right.$ and $\left.S_{\text {low }}\right)$. Two linear 225 reservoirs have been shown to give comparable results to the more parsimonious gamma 226 distribution model (Shaw et al., 2008) and two parallel reservoirs are conceptually closer to 227 an advective-dispersion mechanism (Kirchner, 2000). Here we describe a more complex 228 model that might result in a non-smooth transit time distribution as previously reported by 229 Dunn et al. (2010) and Van der Velde et al. (2011). We therefore track the age of waters in 230 flux using a time stamp tagging each daily incoming and outflowing flux; in addition to the 231 mean annual TT this also allows us to assess the intra-annual variability similar to 232 Hrachowitz et al. (2013):

$234 \quad p_{F, Q}\left(t_{j}-t_{i}, t_{j}\right)=\sum_{n=1}^{N} p_{F, Q_{n}}\left(t_{j}-t_{i}, t_{j}\right) \frac{Q_{n}\left(t_{j}\right)}{Q\left(t_{j}\right)}$

Where $p_{F, Q}$ is the distribution of water age of all contributing fluxes $Q_{n}$ to total discharge $Q$ with $t_{j}$ being the time of exit at the catchment outlet and $t_{i}$ the time of entry with $P$.

The model was calibrated (parameters $a, b, R e, k, \alpha u p S_{p}$, sat $S_{p}$ and $l o w S_{p}$ ) using a multiobjective (flow and tracer) non-dominated sorting genetic algorithm (NSGA2) for optimization applied to each water year starting 01/10/2003 until 30/09/2009 (Deb et al., 2002). Water years were chosen for calibration in an attempt to generate time-variable 
243 parameter sets as basis to assess non-stationary catchment behaviour (Seibert and

244 McDonnell, 2010; Westra et al., 2014). Preliminary tests varying the length of time series for

245 calibration showed that periods $>1$ year lost important information on extreme values whilst

$246<1$ year were insufficient to pick up seasonality effects. The calibration procedure was based

247 on recommendations by Deb et al. (2002) and tested to minimize computation time

248 guaranteeing an exhaustive search across the parameter space. The optimization included

249500 parameter sets (for each of the parameters shown in Figure 2) defined as an initial

250 population. This population was tested and repeatedly constrained over 100 iterations each

251 defined as a generation. This resulted in a total of 50000 tested different parameter

252 combinations. Only the final and best parameter population (500 parameter sets) was

253 retained and used for further analysis which included calculation of simulation bounds

254 representing posterior parameter variability. The retained 500 parameter sets were applied

255 to simulate model output and it was assumed that the results provide a range of accepted

256 models equivalent to a formal uncertainty analysis as shown by Andrews et al. (2012).

257 Calibration objectives were formulated using the modified Kling-Gupta efficiency (KGE)

258 criterion (Kling et al., 2012) simultaneously applied to discharge (KGE_Q) and oxygen-18

$259\left(K G E_{-} \delta^{18} O\right)$ time series. The $K G E$ is a three-dimensional representation (Euclidean distance)

260 of the widely-used Nash-Sutcliffe criterion overcoming some weaknesses of the latter

261 (Schaefli and Gupta, 2007) balancing dynamics (correlation coefficient $r$ ), bias (bias ratio $\beta$ )

262 and variability (variability ratio $\gamma$ ). The following equations mainly use the mean $(\mu)$ and

263 standard deviation ( $\sigma$ ) of observed (subscript obs) against simulated (subscript sim) values:

264

$265 K G E=1-\sqrt{(1-r)^{2}+(1-\gamma)^{2}+(1-\beta)^{2}}$ 
$266 \gamma=\frac{\left(\frac{\sigma_{s i m}}{\mu_{s i m}}\right)}{\left(\frac{\sigma_{o b s}}{\mu_{o b s}}\right)}$

$267 \beta=\frac{\mu_{\text {sim }}}{\mu_{o b s}}$

269 The KGE ranges from - Infinity to a perfect fit of 1 . Modelling was started for each iteration 270 01/01/2000, but calibration was initiated with available isotope data from 01/10/2003 and

271 then continued separately for the following water years. The preceding 2.5 years plus 272 subsequent water years were used as a warming-up period to fill storages and initiate 273 isotope signatures in storages. Observed soil and ground water isotope values were used to 274 initiate the isotope signatures in the storage units (Tetzlaff et al., 2014). The 2.5 years warm275 up period was deemed sufficient after tests running the model showed a negligible impact 276 on model calibration.

\section{$278 \quad$ IV Results}

2794.1 Long-term hydroclimatic and isotopic variability

280 The study period covers the driest period $03 / 04$ in the 42 year available record for the

281 Girnock. The summer drought 2003 followed remarkably wet periods in 00/01 and 01/02

282 which were amongst the wettest years on record (Figure 3). Below average $Q$ persisted for 283 over two years following the 2003 drought, a period which was also characterized by below 284 average $P$; low annual runoff coefficients (RC) reflect this. The year 06/07 was again 
285 extremely wet, with the following two years only slightly below average. Estimated ETP

286 appears quite stable oscillating between 380 and $430 \mathrm{~mm} \mathrm{yr} \mathrm{r}^{-1}$ which reflects the energy-

287 limited environment. Uncertainty in the annual water balance is however most likely

288 affected by underestimated $P$ inputs and measurement errors in the montane environment

289 despite the interpolation method used. In terms of the tracer measurements which began in

290 October 2003, the greatest isotopic range in $Q$ was observed for $03 / 04$ followed by the wet

291 year 06/07 and the lowest range in the year 04/05 (Table 1). This did not, however, always

292 correspond to the input variability. The mean annual isotopic $P$ and $Q$ values are generally

293 similar, but the mean oxygen-18 in $Q$ tended to be more depleted compared to the mean in

$294 P$.

$296 \quad 4.2$ Model simulations

297 The models calibrated to individual water years showed varying, but mostly reasonable 298 performance (Figure 4). The Pareto fronts showed sharp gradients indicating performance 299 close to optimal values (Figure 5). The water year 04/05 gave the best discharge 300 performance with KGE_Q $=0.85$, but among the lowest isotope performance with KGE_ $\delta^{18} \mathrm{O}$ $301=0.7$. The discharge and isotopic dynamics were mostly captured by the simulation ranges 302 (Figure 4) although the highest peak discharges tended to be under-predicted and dry 303 period flows are over-estimated (most notably during summer 2004 and 2005). This most 304 likely resulted from underestimated $P$ input, carry-over effects of the summer 2003 drought 305 resulting in unsaturated storages and a model calibration that compensated both high and 306 low flow periods. Additionally, in some years (2004, 2005 and 2008), under-prediction of 307 summer stream isotope signatures was evident, which would be consistent with 
308 fractionation in the riparian wetlands; a process not considered by the model used here (cf. 309 Birkel et al., 2014). The information content of tracers was variable, being greatest when 310 input variation was most marked and limited if low (Table 1). The information content is 311 probably reflected in the best isotope performance $\left(K G E \_\delta^{18} \mathrm{O}=0.87\right.$ ) achieved for the 312 water year 07/08 where inputs were most variable.

4.3 Dynamic and additional storage dynamics

315 The daily mean $Q$ over the study period showed clear seasonality which mainly reflected the 316 influence of daily mean PET as $P$ was fairly evenly distributed throughout the year (Figure 6).

317 This seasonality was also reflected in the mean daily dynamic storage $S_{d}$ which was derived 318 from the model, though this was slightly lagged with lower (negative storage reflects 319 unsaturated conditions) storage values during summer through to autumn (roughly 320 between May and October). The storage deficits were largely restricted to $S_{\text {up }}$ as both $S_{\text {low }}$ 321 and $S_{\text {sat }}$ on average remained positive due to limited groundwater drawdown and 322 maintenance of saturation in the riparian zone. The $S_{d}$ changes for individual years exhibited 323 marked differences. For example, the daily $S_{d}$ for the 2003 drought showed storage deficits 324 from the end of April, and unsaturated conditions persisted well into 2004. In contrast, the 325 wettest years such as 2007 exhibited persistent positive storage in $S_{\text {sat }}$ and $S_{\text {low }}$. Periods of 326 short, transient storage deficits which appeared limited to $S_{u p}$ occur in May and June, with 327 the wet summer maintaining saturated conditions (and positive storage) throughout the 328 rest of the year. This characteristic of the catchment was reflected in runoff responses to 329 even small rainfall events and the perennial nature of the stream (Tetzlaff et al., 2014). 
331 In the upper hillslopes, the daily $S_{u p}$ estimates showed a highly non-linear relationship with $332 M V_{\text {up }}$ while this relationship was more linear in the saturation area (Figure 7). Furthermore, 333 the storage range and variability was much greater in the hillslopes (Figure 7a) compared to 334 the saturation area (Figure $7 \mathrm{~b}$ ) and groundwater storages (not shown). The greatest storage 335 range could be observed for $03 / 04$ in the hillslopes in contrast to the lowest range in the 336 saturation area which resulted in lower $S_{d}$. Wetter years $(06 / 07$ and $07 / 08)$ could also clearly 337 be distinguished by the largest $S_{\text {Sat }}$ and $M V_{\text {sat }}$ storage ranges in the saturation area. There 338 was less clear distinction for the calibrated MVs in the hillslopes showing significant overlap 339 for most years. High mixing volumes were only evident in response to decreased 340 unsaturated conditions during wetter years of $06 / 07$ and $07 / 08$.

The inter-annual $S_{d}$ variability was clearly related to water balance considerations driven by 344 the magnitude and distribution of $P$ and resulting $Q$ (Figure $8 a$ and $b$, Table 3 ) while the 345 much larger (order of magnitude) calibrated mixing volumes MVs were more complex. We 346 hypothesized that the MVs would vary with hydroclimatic conditions and tested this using 347 the calibrated parameter values from the model. Obviously, this introduced sources of 348 uncertainty; for example the model performance played an important role in the calibration 349 of the catchment storage volumes and derived TT (Figure 8a and c). Linked to this was that 350 tracer simulations were generally better when variability of inputs was most marked in a 351 particular water year, which introduced a stochastic element into each year's calibration. 
352 Despite these limitations, the model results were generally reasonable for both flow and

353 tracers in each year (Figure 4). Consequently, cautious interpretation suggested that the 354 calibrated MVs do produce plausible mean annual TT estimates (Figure 8a and d). However, 355 errors expressed as standard deviations over all simulations were large, which effectively 356 restricts analysis to distinguishing between extreme values. However, this analysis seeks to 357 differentiate relative dynamics rather than absolute values. The $T T$ estimates were lowest 358 for the wettest year (1.4 yr for 06/07). This seemed to be positively related to the variability 359 of the saturation area dynamics (CV_dSAT) (Figure 8d), which reflects the distribution and 360 frequency of catchment $P$ and resulting near-surface flow pathways. The limited $C V \_d S A T$ 361 (0.69) in the driest year 03/04 was also consistent with a higher TT (2.1 yr).

In contrast to the inter-annual assessment using mean annual $T T$, analysis of intra-annual 364 variability used flux water age and the associated controlling factors are conceptualized in 365 Figure 9. The two most contrasting water years (dry 04/05 and wet 06/07) were used to 366 show the interplay of tracer damping (Figure 9a), the frequency of near-surface flow 367 pathway contributions to $Q$ (Figure 9b), the frequency of hydrological connectivity in the 368 form of expanded saturation areas adjacent to the stream (Figure 9c) and resulting $S_{d}$ 369 variability (Figure 9d) on clearly non-stationary water ages (Figure 9e). The non-stationarity 370 of flux water ages is further emphasized if expressed as cumulative distribution functions 371 CDF. Shorter water age could be associated with runoff events and mostly younger waters 372 (in the order of weeks to a few months) originating from the connected saturation areas 373 contributing to $Q$ via near-surface flow pathways (saturation overland flow). In contrast, contributions of older groundwaters ( $>4$ years in age) during drier conditions and with 
375 reduced connectivity resulted in increased water age. In the case of 04/05, the less frequent

376 expansion of the saturated areas resulted in a lower overall contribution of near surface

377 flow paths to the annual runoff, and a greater proportion of deeper groundwater

378 contributions. The resulting greater mixing increased water age and reduced the influence

379 of the younger waters. As a result, the model derived estimate of the daily catchment water

380 age can vary over the course of a year between a couple of months to $>4$ years. When the

381 daily flux water ages were used to derive mean annual values these resulted in 1.1 years for

382 the wet year 06/07 and in 1.6 years for the drier year 04/05 (taken from Figure 9e).

384 V Discussion

$385 \quad 5.1$ Internal model storage dynamics

386 In this study we integrated isotope oxygen-18 transport into a conceptual rainfall-runoff

387 model to track internal dynamic storage changes and the additional mixing volumes needed

388 to match observed tracer damping in streamwater. This built on earlier work by Birkel et al.,

$3892011 \mathrm{~b}$ and is conceptually similar to the approach of Hrachowitz et al. (2013) which used

390 Chloride as a conservative tracer. However, in this intensively monitored catchment, the

391 model was developed using the dominant process concept reflecting the landscape controls

392 on runoff generation including dynamic saturation areas, freely draining hillslopes and

393 significant groundwater storage. Within this framework, a key goal was minimizing the

394 number of calibrated parameters (Sivakumar, 2004). Central to this landscape-based

395 approach was the conceptualization of dynamic hydrological connectivity that was based on

396 empirical data (Ali et al., 2014). This dynamic connectivity incorporates - when necessary - a 
397 high-degree of non-linearity specifically in terms of storage dynamics and resulting near398 surface runoff generation mechanisms which are broadly consistent with the process-based 399 insights from the catchment (Tetzlaff et al., 2014). In addition, the constrained initial 400 parameter ranges (Table 2) used for calibration match the hydrochemically determined 401 groundwater contributions from previous observations (Birkel et al., 2010). In other words 402 the model performs an internal hydrograph separation consistent with geochemical source 403 tracers (alkalinity) to help ensure simple conceptualisation of process realism as advocated 404 by Kirchner (2006).

405

406 The model was calibrated using a state-of-the-art multi-objective optimization algorithm 407 (NSGA2 by Deb et al., 2002) minimizing the modified Kling-Gupta efficiency criterion (Kling 408 et al., 2012). This allowed simultaneous calibration against tracer and discharge data, 409 overcoming reported limitations of single performance measures such as the widely used 410 Nash-Sutcliffe efficiency (Schaefli and Gupta, 2007). Recognizing that no optimal solution 411 can be found with an eight-parameter model (e.g. Beven, 2012) the sharp gradients of the 412 Pareto fronts indicate that solutions fall at least close to optimum (achievable with this 413 model) for the calibration targets and are assumed to be behavioural representations of the 414 system (Figure 4). Nevertheless, we acknowledge the inherent uncertainties and limitations 415 of the data sources, our simple conceptual model approach and the variability introduced 416 using sub-periods for calibration. Nevertheless, these sub-periods allow the generation of 417 time-variable parameter sets and subsequently an insight into non-stationary catchment 418 behaviour similar to Wresta et al. (2014). 
420 Model storage dynamics and resulting water age - as expected - depend on model

421 performance and parameter sensitivity (e.g. Dunn et al., 2010). Furthermore, concerns have

422 been expressed as to what degree simple conceptual models are able to reproduce complex

423 non-linear behaviour in the form of e.g. hysteresis (Beven, 2012). Nevertheless, model

424 simulations can be useful learning tools for understanding system dynamics and it is in this

425 sense that we argue our approach, although in some ways qualitative, provides useful

426 insights. Results showed, for example, that there is a clear seasonal correspondence

427 between the simulated dynamic storage and observed hydrometric data (Figure 6). This is

428 despite the fact that the Girnock does not exhibit a simple non-linear storage-discharge

429 relationship (Kirchner, 2009) at daily or sub-daily time scales (Birkel et al., 2011a). It also

430 becomes apparent from the storage simulations that the drought period 2003 showed a

431 marked persistence well into the second half of 2004 in terms of unsaturated (negative)

432 storage conditions (Figure 6). Other modelling (not shown here) has suggested that the only

433 other occasion when this occurred was for the second most severe drought on record in the

434 1970s. This is not visible from discharge simulations alone and is an insight from the storage

435 tracking undertaken in this study. Furthermore, simulated dynamic storage was consistent

436 with observed soil moisture and groundwater dynamics recently reported in Birkel et al.

437 (2014) and Tetzlaff et al. (2014). This included marked non-linear dynamics on the hillslopes

438 and increasingly linear behaviour in the well-buffered saturation areas.

439

440 In contrast to the dynamic storage (which is a model state), the additional storage needed

441 for mixing is based on calibrated parameters (e.g. Barnes and Bonell, 1996). Since tracer

442 transport was directly coupled to water transport (Equation 3) the corresponding mixing 
443 assumption is that of "instantaneous" and "well-mixed" reservoirs to produce the observed

444 tracer damping in stream. This has been shown to be an overly simplistic concept (e.g.

445 Fenicia et al., 2010; Botter et al., 2012) with advective-dispersion processes most likely

446 controlling mixing in real world situations (Kirchner and Neal, 2013). That said, Tetzlaff et al.

447 (2014) showed that virtually all precipitation damping in the catchment occurs in the upper

$4480.3 \mathrm{~m}$ of the catchments organic soils. Nevertheless, in this study we relaxed this

449 assumption using the model's dynamic, non-linear connectivity to convert additional

450 storage parameters into different mixing volumes according to the wetness state of the

451 catchment. This resulted in a type of partial mixing mechanism whilst maintaining our key

452 goal of keeping model parameters to a minimum. However, the effect of such a partial

453 mixing mechanism could really only be discerned for climatically extreme periods (Figure 7)

454 similar to the results of Hrachowitz et al. (2013). The incorporation of additional parameters

455 could improve this, but this is statistically difficult to justify. Work from Benettin et al. (2013)

456 might help in this regard to pre-define mixing assumptions based on advection-dispersion

457 models. Other types of integrated flow-tracer models such as the multiple interactive

458 pathways approach by Davies et al. (2011) also allows the direct incorporation of partial

459 mixing with minimal parameterization. However, in wet environments like the Scottish

460 Highlands, the relatively even distribution of $P$ throughout the year, in combination with

461 high water storage in saturated organic soils (e.g. histosols) fringing the riparian zone seems

462 to integrate partial mixing in other geographic source areas resulting in a more complete

463 mixing at the catchment scale. Therefore, Tetzlaff et al. (2014) used the term "isostat" to

464 describe this characteristic mixing behaviour of the saturation areas. 
4665.2 Long-term storage and water age's response to hydroclimatic variability

467 Storage simulations showed that much larger mixing volumes (i.e. an order of magnitude)

468 determine TTs rather than dynamic storage changes as shown by e.g. Birkel et al. (2011a).

469 Building on previous work, this longer-term data analysis clearly demonstrated the non-

470 stationary character of mean annual TTs (Figure 8) oscillating between 1.4 and 2.4 years

471 (Table 3). It is clear that the interpretation of TTS is relative due to large uncertainties as

472 expressed in the error bars in Figure 8d and must therefore be cautious. However, despite

473 not being exactly the same (e.g. Botter et al., 2011), the latter TT values were consistent

474 with previously determined mean transit time estimates in the catchment applying lumped

475 convolution integral methods and spectral analysis (Hrachowitz et al. 2010, Kirchner et al.,

476 2010). Furthermore, the flux water ages derived from daily tracking of model states and

477 fluxes (Hrachowitz et al., 2013) to assess intra-annual variability if used to derive mean

478 annual water age were shorter than the $T T$ (e.g. 1.1 against $1.4 \mathrm{yr}$ for 06/07). They do,

479 however, also fall well within the estimated errors of TTs. Both water age and TT

480 corresponded to climate extremes (specifically wetter periods decrease $T T$ and flux water

481 age) as previously reported by Hrachowitz et al. (2011).

The non-stationary character of mean annual TTS could be related to the variability of saturation area dynamics (Figure 8) or - in other words - hydrological connectivity, which is based on antecedent wetness rather than topographic controls (Ali et al., 2014). This finding 486 also holds for intra-annual water ages and is consistent with work by Roa-Garcia and Weiler 487 (2010) in that high antecedent wetness increases flow path connectivity which results in shorter water transit times and reduced recharge and deeper mixing. In the Girnock, this is 
489 reflected in the dominance of near-surface runoff generation processes mostly in form of 490 saturation overland flow which contribute increasingly younger waters to streamflow under 491 high-frequency and large saturation area connectivity (Figure 9e - flux water age estimates 492 and derived (DF).

Despite these tentative conclusions, we also recognize the limitations of stable water isotopes in determining such mixing volumes (Stewart et al., 2010) due to dependence on input variability and the degree of damping in output (Kirchner et al., 2010). This was reflected in better simulations where input variability was greater and damping was lower (Figure 8 , Table 1). It might be that the lowest flows are dominated by storage levels with a older water age than can be detected by simple isotope input-output variability (which in this model is represented by calibrated additional storage parameters to be able to 501 reproduce the degree of observed damping). Recently, Peters et al. (2013) showed how 502 long-term Tritium data could be used to estimate total catchment storage and fluctuations 503 at smaller scales and relatively impermeable bedrock substrate.

505 The quantification of total catchment storage, however, remains a challenge (hence we 506 preferred to use the term catchment storage rather than total catchment storage to 507 emphasize this), but we hope to have presented a step in the right direction using coupled 508 tracer and hydrology models. Certainly recent geophysical surveys in the Girnock (J. 509 Bradford, Boise State University, Pers. Comm.) have indicated up to $40 \mathrm{~m}$ of saturated drift in 510 valley bottom areas. However, this drift has a low porosity ( 10-20\%) and low hydraulic 
511 conductivity $\left(\sim 10 \mathrm{~mm} \mathrm{~d}^{-1}\right)$ so catchment scale storage is limited to about $1000-2000 \mathrm{~mm}$.

512 These figures are of the same order of magnitude as those derived in the current study, and 513 other tracer-based studies using more conventional convolution integral models (Tetzlaff et 514 al., 2014).

515

\section{VI Conclusions}

517 In this study we showed how the interplay of tracer dynamics, hydrological connectivity and 518 catchment storage affects non-stationary water ages using longer-term hydrometric and 519 isotopic data sets. We also have shown how hydroclimatic variability relates to catchment 520 storage dynamics and resulting time-variable water age. A coupled tracer and runoff model 521 showed that relatively modest dynamic storage fluctuations $(<100 \mathrm{~mm})$ account for seasonal 522 flow variability in most years including the driest year 2003 (on a 42 year data record). 523 However, storage volumes an order of magnitude greater (>1000 $\mathrm{mm}$ ) need to be invoked to 524 account for the mixing needed to simulate isotope dynamics. This clearly demonstrated the 525 non-stationarity of catchment water age at daily and annual time scales, but in the Scottish 526 environment these only vary by a factor of two in the more extreme wet and dry periods. 527 Such extreme conditions have a major influence on hydrological connectivity and 528 contributing flow pathways which in turn affect the proportion of younger near-surface 529 waters ( 10 to 50 days old) or older groundwaters ( 1 to 10 years old) reaching the stream. 530 However, in most years, the riparian wetlands represent a large water storage available for 531 mixing which acts as an "isostat" moderating isotope variability and limiting the time 532 variance of water age. Even though, the "isostat" effect is most likely more prominent in 533 northern upland catchments with histosols fringing the stream, the methods and model 
534 concepts could easily be transferred and tested at other sites. Despite the limitations

535 associated with using isotope tracers and inevitable model errors, we present a step

536 towards characterizing catchment storage and its associated dynamics. We conclude that

537 much can be learnt from long-term analysis of hydrometric and isotopic data and their

538 integration in hydrological models to understand the potential impact of extreme climatic

539 events on hydrological systems. Specifically, the approach helps assess the degree to which

540 such extremes are mediated by internal dynamic storage changes and additional storage

541 available for mixing.

542

\section{Acknowledgements}

544 We would like to gratefully acknowledge data provided by SEPA, lain Malcolm (MSS) and 545 BADC. Mark Speed, Susan Waldron and many MSS staff helped with sample collection and 546 lab analysis. We thank the European Research Council ERC (project GA 335910 VEWA) for 547 funding and are grateful for constructive comments provided by three anonymous 548 reviewers

549

550 
Ali G, Birkel C, Tetzlaff D, Soulsby C, McDonnell JJ, Tarolli P. 2014. A comparison of wetness indices for the prediction of connected saturated areas under contrasted conditions. Earth Surface Processes and Landforms. doi: 10.1002/esp.3506.

555 Andrews F, Croke B, Jakeman A. 2011. An open software environment for hydrological model 556 assessment and development. Environmental Modelling \& Software 26: 1171-1185. 557 doi:10.1016/j.envsoft.2011.04.006.

558 Barnes CJ, Bonell M. 1996. Application of unit hydrograph techniques to solute transport in 559 catchments. Hydrol. Processes. 10: 793-802.

560 Beven K. 2012. Rainfall-runoff modelling: The Primer. Second edition. Wiley-Blackwell.

561 Benettin P, Rinaldo A, Botter G. 2013. Kinematics of age mixing in advection-dispersion models. 562 Water Resour. Res. 49: 8539-8551. doi:10.1002/2013WR014708.

563 Birkel C, Tetzlaff D, Dunn SM, Soulsby C. 2010. Towards simple dynamic process conceptualization in 564 rainfall-runoff models using multi-criteria calibration and tracers in temperate, upland catchments. 565 Hydrol. Process. 24: 260-275.

566 Birkel C, Tetzlaff D, Dunn SM, Soulsby C. 2011a. Using time domain and geographic source tracers to 567 conceptualize streamflow generation processes in lumped rainfall-runoff models. Water Resources 568 Research. 47. DOI: 10.1029/2010WR009547

569 Birkel C, Soulsby C, Tetzlaff D. 2011b. Modelling catchment-scale water storage dynamics: 570 reconciling dynamic storage with tracer-inferred passive storage. Hydrol. Process. 25: 3924-3936. 571 doi: 10.1002/hyp.8201.

572 Birkel C, Soulsby C, Tetzlaff D. 2014. Developing a consistent process-based conceptualization of 573 catchment functioning using measurements of internal state variables. Water Resources Research. 574 Doi: 10.1002/2013WR014925.

575 Bishop K, Seibert J, Nyberg L, Rodhe A. 2011. Water storage in a till catchment. II: Implications of 576 transmissivity feedback for flow paths and turnover times. Hydrol. Process. 25: 3950-3959. 577 doi: 10.1002/hyp.8355

578 Botter G, Bertuzzo E, Rinaldo A. 2011. Catchment residence and travel time distributions: The master 579 equation. Geophys. Res. Lett. 38: L11403. doi:10.1029/2011GL047666.

580 Botter G. 2012. Catchment mixing processes and travel time distributions. Water Resour. Res. 48: 581 W05545. doi:10.1029/2011WR011160.

582 Brooks JR, Barnard HR, Coulombe R, McDonnell JJ. 2009. Ecohydrologic separation of water between 583 trees and streams in a Mediterranean climate. Nature Geoscience 3: $100-104$.

584 Brauer C., Teuling AJ, Torfs PJJF, Uijlenhoet R. 2013. Investigating storage-discharge relations in a 585 lowland catchment using hydrograph fitting, recession analysis, and soil moisture data. Water 586 Resour. Res. 49: 4257-4264. doi:10.1002/wrcr.20320.

587 Capell R, Tetzlaff D, Soulsby C. 2013. Will catchment characteristics moderate the projected effects 588 of climate change on flow regimes in the Scottish Highlands?, Hydrol. Process. 27: 687-699. doi: 589 10.1002/hyp.9626

590 Davies J, Beven K, Rodhe A, Nyberg L, Bishop K. 2013. Integrated modelling of flow and residence 591 times at the catchment scale with multiple interacting pathways. Water Resour. Res. 49: 4738-4750, 592 doi:10.1002/wrcr.20377. 
593 Deb K, Pratap A, Agarwal S, Meyarivan T. 2002. A fast and elitist multi-objective genetic algorithm: 594 NSGA-II. IEEE Transaction on Evolutionary Computation 6(2): 181-197.

595 Dunn SM, Birkel C, Tetzlaff D, Soulsby C. 2010. Transit time distributions of a conceptual model: their 596 characteristics and sensitivities. Hydrol. Process. 24: 1719-1729. doi: 10.1002/hyp.7560.

597 Fenicia F, Wrede S, Kavetski D, Pfister L, Hoffmann L, Savenije HHG, McDonnell JJ. 2010. Assessing 598 the impact of mixing assumptions on the estimation of streamwater mean residence time. Hydrol. 599 Process. 24(12): 1730-1741. doi: 10.1002/hyp.7595.

600 Heidbüchel I, Troch PA, Lyon SW, Weiler M. 2012. The master transit time distribution of variable 601 flow systems. Water Resour. Res. 48: W06520. doi: 10.1029/2011WR011293.

602 Hrachowitz M, Soulsby C, Tetzlaff D, Malcolm IA, Schoups G. 2010. Gamma distribution models for 603 transit time estimation in catchments: Physical interpretation of parameters and implications for 604 timevariant transit time assessment. Water Resour. Res. 46: W10536. doi:10.1029/2010WR009148.

605 Hrachowitz M, Soulsby C, Tetzlaff D, Malcolm IA. 2011. Sensitivity of mean transit time estimates to 606 model conditioning and data availability. Hydrol. Processes 25(6): 980-990. doi:10.1002/hyp.7922.

607 Hrachowitz M, Savenije H, Bogaard TA, Tetzlaff, Soulsby C. 2013. What can flux tracking teach us 608 about water age distribution patterns and their temporal dynamics? Hydrol. Earth Syst. Sci. 17: 533609 564. doi: 10.5194/hess-17-533-2013.

610 Kirchner JW, Feng X, Neal C. 2000. Fractal stream chemistry and its implications for contaminant 611 transport in catchments. Nature 403: 524-527. doi:10.1038/35000537.

612 Kirchner JW. 2006. Getting the right answers for the right reasons: Linking measurements, analyses, 613 and models to advance the science of hydrology. Water Resour. Res. 42: W03S04. doi: $61410.1029 / 2005$ WR004362.

615 Kirchner JW. 2009. Catchments as simple dynamical systems: Catchment characterization, 616 rainfall-runoff modeling, and doing hydrology backward. Water Resour. Res. 45: W02429. doi: 617 10.1029/2008WR006912.

618 Kirchner JW, Tetzlaff D, Soulsby C. 2010. Comparing chloride and water isotopes as hydrological 619 tracers in two Scottish catchments. Hydrol. Process. 24: 1631-1645. DOI: 10.1002/hyp.7676.

620 Kirchner JW, Neal C. 2013. Universal fractal scaling in stream chemistry and its implications for solute 621 transport and water quality trend detection. PNAS 110: 12213-12218. 622 doi/10.1073/pnas.1304328110.

623 Kling H, Fuchs M, Paulin M. 2012. Runoff conditions in the upper Danube basin under an ensemble 624 of climate change scenarios. J. Hydrol. 424-425: 264-277. doi:10.1016/j.jhydrol.2012.01.001.

625 Maloszewski P, Zuber A. 1982. Determining the turnover time of groundwater systems with the aid 626 of environmental tracers, 1. Models and their applicability. J. Hydrol. 57: 207-231.

627 McDonnell JJ, Beven K. 2014. Debates-The future of hydrological sciences: A (common) path 628 forward? A call to action aimed at understanding velocities, celerities, and residence time 629 distributions of the headwater hydrograph. Water Resour. Res., 50: doi:10.1002/2013WR015141.

630 McMillan H, Tetzlaff D, Clark M, Soulsby C. 2012. Do time-variable tracers aid the evaluation of 631 hydrological model structure? A multimodel approach. Water Resour. Res. 48: W05501. 632 doi:10.1029/2011WR 011688.

633 McNamara JP, Tetzlaff D, Bishop K, Soulsby C, Seyfried M, Peters NE, Aulenbach BT, Hooper R. 2011. 634 Storage as a Metric of Catchment Comparison. Hydrol. Process. 25. DOI: 10.1002/hyp.8113 
635 Peters NE, Burns D, Aulenbach BT. 2013. Evaluation of High-Frequency Mean Streamwater Transit636 Time Estimates Using Groundwater Age and Dissolved Silica Concentrations in a Small Forested 637 Watershed. Aquat Geochem, DOI: 10.1007/s10498-013-9207-6

638 Rinaldo A, Beven KJ, Bertuzzo E, Nicotina L, Davies J, Fiori A, Russo D, Botter G. 2011. Catchment 639 travel time distributions and water flow in soils. Water Resour. Res. 47: W07537.

640 doi:10.1029/2011WR010478.

641 Roa-García MC, Weiler M. 2010. Integrated response and transit time distributions of watersheds by 642 combining hydrograph separation and long-term transit time modeling. Hydrology and Earth System 643 Sciences 14: 1537-1549, DOI: 10.5194/hess-14-1537-2010, 2010.

644 Rodell M, Velicogna I, Famiglietti JS. 2009. Satellite-based estimates of groundwater depletion in 645 India. Nature 460: 999-1002. DOI: 10.1038/nature08238.

646 Salve R, Rempe DM, Dietrich WE. 2012. Rain, rock moisture dynamics, and the rapid response of 647 perched groundwater in weathered, fractured argillite underlying a steep hillslope. Water Resour. 648 Res. 48: W11528. doi: 10.1029/2012WR012583.

649 Schaefli B, Gupta H. 2007. Do Nash values have value? Hydrological Processes 21: 2075-2080. DOI: 650 10.1002/hyp.6825.

651 Seibert J, McDonnell J.J. 2010. Land-cover impacts on streamflow: A change-detection modeling 652 approach that incorporates parameter uncertainty. Hydrological Sciences Journal 55(3): 316-332.

653 Shaw S, Harpold AA, Taylor JC, Walter MT. 2008. Investigating a high resolution, stream chloride 654 time series from the Biscuit Brook catchment, Catskills, NY. J. Hydrol. 348: 245-256.

655 Sivakumar B. 2004. Dominant processes concept in hydrology: moving forward. Hydrological 656 Processes 18: 2349-2353.

657 Soulsby C, Tetzlaff D, van den Bedem N, Malcolm IA, Bacon PJ, Youngson AF. 2007. Inferring 658 groundwater influences on surface water in montane catchments from hydrochemical surveys of 659 springs and streamwaters. J. Hydrol. 333: 199- 213.

660 Soulsby C, Neal C, Laudon H, Burns DA, Merot P, Bonell M, Dunn SM, Tetzlaff D. 2008. Catchment 661 data for process conceptualization: Simply not enough? Hydrol. Processes 22: 2057- 2061.

662 Soulsby C, Tetzlaff D, Hrachowitz M. 2009. Tracers and transit times: windows for viewing catchment 663 scale storage? Hydrol. Process. 23: 3503-3507. DOI: 10.1002/hyp.7501

664 Stewart MK, Morgenstern U, McDonnell JJ. 2010. Truncation of stream residence time: How the use 665 of stable isotopes has skewed our concept of streamwater age and origin Hydrological Processes 24: $6661646-1659$.

667 Tetzlaff D, Soulsby C, Waldron S, Malcolm IA, Bacon PJ, Dunn SM, Lilly A. 2007. Conceptualisation of 668 runoff processes using GIS and tracers in a nested mesoscale catchment. Hydrological Processes 21: $669 \quad 1289-1307$.

670 Tetzlaff D, Uhlenbrook S, Eppert S, Soulsby C. 2008. Does the incorporation of process 671 conceptualisation and tracer data improve the structure and performance of a simple rainfall-runoff 672 model in a Scottish mesoscale catchment? Hydrological Processes 22: 2461-2474.

673 Tetzlaff D, Birkel C, Dick J, Soulsby C. 2014. Storage dynamics in hydropedological units control 674 hillslope connectivity, runoff generation and the evolution of catchment transit time distributions. 675 Water Resour. Res., doi: 10.1002/2013WR014147.

676 van der Velde Y, de Rooij GH, Rozemeijer JC, van Geer FC, Broers HP. 2010. Nitrate response of a 677 lowland catchment: On the relation between stream concentration and travel time distribution 678 dynamics. Water Resour. Res. 46: W11534. doi:10.1029/2010WR009105. 
679 Westra S, Thyer M, Leonard M, Kavetski D, Lambert M. 2014. A strategy for diagnosing and 680 interpreting hydrological model nonstationarity. Water Resour. Res., 50: 5090-5113,

681 doi:10.1002/2013WR014719.

682 Zreda M, Shuttleworth WJ, Zeng X, Zweck C, Desilets D, Franz TE, Rosolem R. 2012. COSMOS: the 683 COsmic-ray Soil Moisture Observing System. Hydrol. Earth Syst. Sci. 16: 4079- 4099. 684 doi:10.5194/hess-16-4079-2012, 2012.

685 Zuber A. 1986. On the interpretation of tracer data in variable flow systems. J. Hydrol. 86: 45-57. 
688

689

690

691

692

693

694

695

696

697

698

699

700

701

702

703
TABLES

Table 1: Isotopic signatures for input $\left(P_{-} \delta^{18} \mathrm{O}\right)$ and output $\left(Q_{-} \delta^{18} \mathrm{O}\right)$ annual mean, minimum, maximum (in brackets), isotopic ranges (in per mil) and the coefficient of variation (CV) over the study period. The annual water balance and the CV of the \% catchment saturation area extent (dSAT) is also given.

Table 2: Mean parameter values and ranges expressed as minimum and maximum values (in parenthesis) for each annual time window derived from the best parameter (500 parameter sets) population after multi-objective calibration. This indicates the accepted parameter variability and mean performance measures (KGE) derived from the Pareto fronts in Figure 4. The initial parameter ranges were constrained based on previous tracer-based studies (Birkel et al., 2010).

Table 3: Storage totals $(S)$ are given for the annual means of the individual calibration periods in the context of mean annual transit times (TT). Note that $S_{u p}$ is only given for values exceeding the baseline when lateral and vertical fluxes were generated from this reservoir. 
Figure 1: Location and topography of the Girnock experimental catchment.

Figure 2: The model concept used to simulate discharge and oxygen-18. Three reservoirs (upper, lower and saturation area) conceptualize water and tracer fluxes with associated dynamic storage $\left(S_{u p}, S_{\text {low }}\right.$ and $\left.S_{\text {sat }}\right)$ and additional storage available for mixing ( $u p S_{p}$, low $S_{p}$ and $s a t S_{p}$ ). The latter calibrated additional storage parameters are converted into dynamic mixing volumes MV according to wetness state (dSAT) assuming that during expansion of the saturation areas (> wetness) more additional storage is available for mixing contrary to the hillslopes. Note that calibrated parameters are shown in red.

Figure 3: Mean annual water balance ( $P, Q$ and $P E T)$ and runoff coefficients (RC) emphasize the climate variability in form of the drought period 2003.

Figure 4: Discharge and isotope simulations are plotted using the range of the individual calibration periods. The simulation ranges were derived from the best parameter population (500 sets) of each calibration window (shown as Pareto fronts in Figure 5 with parameter ranges given in Table 2). Simulation bounds indicate parameter variability as a proxy for uncertainty. Note that the same colour code is used throughout and that discharge is plotted on a logarithmic scale.

Figure 5: Pareto fronts of annual time windows (water years) derived from multi-objective calibration (NSGA2) using discharge and $\delta^{18} \mathrm{O}$ time series. Performance was assessed using the Kling-Gupta efficiency (KGE).

Figure 6: a) Daily mean rain (blue), discharge (black) and PET. b) Model derived mean daily dynamic storage ( $S_{d}$ - blue line), daily mean individual storages (dashed lines) and daily dynamic storage for selected years (2003, 2004 and 2007). Note that the scale is Julian days emphasizing the carry-over effect of the drought period 2003.

Figure 7: a) Active hillslope and b) saturation area storages are individually plotted against dynamic mixing volumes for the six complete water years spanning the study period 2003 to 2009.

Figure 8: Annual dynamic and additional storage available for mixing (sum of three reservoirs, respectively) are shown in relation to a) mean annual discharge $Q$ and resulting mean transit time (TT) estimates. b) shows the dynamic storage against additional mixing volumes and c) show the relationship of precipitation isotope input variability (CV $\mathrm{P}_{-} \delta^{18} \mathrm{O}$ ) to model performance (KGE) simulating stream $\delta^{18} \mathrm{O}$ and d) the variability of catchment wetness (CV dSAT) to TT. Error bars reflect standard deviations across all simulations reflecting interannual variability. 
Figure 9: The conceptual diagram shows the main controls in terms of a) tracer damping (measured oxygen-18 input-output time series), b) near-surface flow pathways (daily histogram), c) connectivity (daily histogram) and d) dynamic storage (simulated time series) on e) streamwater age exemplified using two contrasting (dry 2004/05 in red and wet $2006 / 07$ in orange) water years. The degree of tracer damping is highly variable on an interannual basis, but reflects the additional storage needed for mixing and resulting streamwater age time series and CDF (see also Figure 8 and Table 2 for mean annual average values). Note that the time series are coloured according to the previously used scheme. 


\section{TABLES}

2 Table 1: Isotopic signatures for input $\left(P_{-} \delta^{18} O\right)$ and output $\left(Q_{-} \delta^{18} O\right)$ annual mean, minimum, 3 maximum (in brackets), isotopic ranges (in per mil) and the coefficient of variation (CV) over 4 the study period. The annual water balance and the $\mathrm{CV}$ of the $\%$ catchment saturation area 5 extent (dSAT) is also given.

\begin{tabular}{|c|c|c|c|c|c|c|c|c|c|}
\hline $\begin{array}{l}\text { Water } \\
\text { year }\end{array}$ & $P_{-} \delta^{18} 0$ & $\begin{array}{l}P_{-} \delta^{18} O \\
\text { range }\end{array}$ & $\begin{array}{l}\text { CV } \\
P_{-} \delta^{18} O\end{array}$ & $Q \_\delta^{18} O$ & $\begin{array}{l}Q \text { Q_ } \delta^{18} O \\
\text { range }\end{array}$ & $\begin{array}{l}\text { CV } \\
Q \_\delta^{18} O\end{array}$ & $\begin{array}{l}\mathrm{P}(\mathrm{mm} \\
\left.\mathrm{yr}^{-1}\right)\end{array}$ & $\begin{array}{l}Q(m m \\
\left.y^{-1}\right)\end{array}$ & $\begin{array}{l}\text { CV } \\
\text { dSAT }\end{array}$ \\
\hline $03 / 04$ & $\begin{array}{c}-9.03[-16.1,- \\
5.2]\end{array}$ & 10.9 & 0.34 & $\begin{array}{c}-8.88[-11.7,- \\
7.6]\end{array}$ & 4.1 & 0.09 & 845 & 435 & 0.69 \\
\hline $04 / 05$ & $\begin{array}{c}-7.74[-11.5,- \\
3.2] \\
\end{array}$ & 8.3 & 0.26 & $\begin{array}{c}-8.21[-9.1,- \\
7.3] \\
\end{array}$ & 1.9 & 0.04 & 766 & 461 & 0.68 \\
\hline 05/06 & $\begin{array}{c}-8.28[-16.0,- \\
3.7] \\
\end{array}$ & 12.4 & 0.32 & $\begin{array}{c}-8.50[-10.5,- \\
7.0] \\
\end{array}$ & 3.5 & 0.07 & 821 & 466 & 0.71 \\
\hline 06/07 & $\begin{array}{c}-8.33[-15.9,- \\
5.6]\end{array}$ & 10.3 & 0.25 & $\begin{array}{c}-8.54[-10.9,- \\
7.4]\end{array}$ & 3.5 & 0.06 & 1038 & 740 & 0.81 \\
\hline 07/08 & $\begin{array}{c}-8.49[-17.5,- \\
2.9]\end{array}$ & 14.6 & 0.38 & $\begin{array}{c}-8.67[-9.9,- \\
6.9]\end{array}$ & 3.0 & 0.08 & 835 & 593 & 0.73 \\
\hline 08/09 & $\begin{array}{c}-8.49[-18.5,- \\
3.4]\end{array}$ & 14.9 & 0.34 & $\begin{array}{c}-8.47[-10.6,- \\
7.2] \\
\end{array}$ & 3.4 & 0.09 & 843 & 485 & 0.63 \\
\hline
\end{tabular}

6

7

8 
23 Table 2: Mean parameter values and ranges expressed as minimum and maximum values (in parenthesis) for each annual time window derived from the best parameter (500 parameter sets) population after multi-objective calibration. This indicates the accepted parameter variability and mean performance measures (KGE) derived from the Pareto fronts in Figure 4. The initial parameter ranges were constrained based on previous tracer-based studies

28 (Birkel et al., 2010).

\begin{tabular}{|c|c|c|c|c|c|c|c|c|c|c|}
\hline & $a$ & $b$ & $\operatorname{Re}$ & $k$ & $\alpha$ & $u p S_{p}$ & satS $_{p}$ & lows $S_{p}$ & $\begin{array}{l}\text { Mean } \\
\text { KGE_Q }\end{array}$ & $\begin{array}{l}\text { Mean } \\
\text { KGE } \\
\delta^{18} \mathrm{O}\end{array}$ \\
\hline $\begin{array}{l}\text { Initial } \\
\text { range }\end{array}$ & $\begin{array}{l}{[0.2,} \\
0.8]\end{array}$ & $\begin{array}{l}{[0.0001,} \\
0.1]\end{array}$ & $\begin{array}{l}{[0.2,} \\
0.9]\end{array}$ & $\begin{array}{l}\text { [0.001, } \\
0.1]\end{array}$ & {$[0.1,0.9]$} & $\begin{array}{l}{[0,} \\
1000]\end{array}$ & $\begin{array}{l}{[0,} \\
1000]\end{array}$ & $\begin{array}{l}{[0,} \\
1000]\end{array}$ & & \\
\hline Unit & $d^{-1}$ & $d^{-1}$ & $d^{-1}$ & $\mathrm{~d}^{-1}$ & $(-)$ & $\mathrm{mm}$ & $\mathrm{mm}$ & $\mathrm{mm}$ & $(-)$ & $(-)$ \\
\hline $03 / 04$ & $\begin{array}{c}0.39 \\
(0.2, \\
0.6)\end{array}$ & $\begin{array}{r}0.002 \\
(0.001, \\
0.004)\end{array}$ & $\begin{array}{r}0.74 \\
(0.35 \\
0.79)\end{array}$ & $\begin{array}{r}0.005 \\
(0.001 \\
0.016)\end{array}$ & $\begin{array}{r}0.84 \\
(0.66, \\
0.9)\end{array}$ & $\begin{array}{r}125 \\
(102, \\
386)\end{array}$ & $8(4,59)$ & $\begin{array}{r}878 \\
(277, \\
899)\end{array}$ & 0.40 & 0.80 \\
\hline $04 / 05$ & $\begin{array}{r}0.47 \\
(0.36, \\
0.61) \\
\end{array}$ & $\begin{array}{r}0.006 \\
(0.003 \\
0.007) \\
\end{array}$ & $\begin{array}{r}0.63 \\
(0.47, \\
0.8) \\
\end{array}$ & $\begin{array}{r}0.070 \\
(0.04,0.1) \\
\end{array}$ & $\begin{array}{r}0.47 \\
(0.33 \\
0.57) \\
\end{array}$ & $\begin{array}{r}255(83, \\
583)\end{array}$ & $\begin{array}{r}36(2.1, \\
47)\end{array}$ & $\begin{array}{r}931 \\
(370, \\
990) \\
\end{array}$ & 0.84 & 0.66 \\
\hline $05 / 06$ & $\begin{array}{r}0.43 \\
(0.28, \\
0.48) \\
\end{array}$ & $\begin{array}{r}0.009 \\
(0.002, \\
0.03) \\
\end{array}$ & $\begin{array}{r}0.57 \\
(0.44, \\
0.78) \\
\end{array}$ & $\begin{array}{c}0.019 \\
(0.01 \\
0.04) \\
\end{array}$ & $\begin{array}{r}0.79 \\
(0.54, \\
0.86) \\
\end{array}$ & $\begin{array}{r}641 \\
(340, \\
902) \\
\end{array}$ & $\begin{array}{r}38(3, \\
75) \\
\end{array}$ & $\begin{array}{r}742 \\
(248, \\
931) \\
\end{array}$ & 0.73 & 0.76 \\
\hline 06/07 & $\begin{array}{r}0.54 \\
(0.26, \\
0.71)\end{array}$ & $\begin{array}{r}0.011 \\
(0.004 \\
0.06)\end{array}$ & $\begin{array}{r}0.56 \\
(0.29, \\
0.74)\end{array}$ & $\begin{array}{r}0.069 \\
(0.02,0.1)\end{array}$ & $\begin{array}{l}0.59 \\
(0.3, \\
0.78)\end{array}$ & $\begin{array}{r}139(62, \\
215)\end{array}$ & $\begin{array}{r}53(32 \\
122)\end{array}$ & $\begin{array}{r}768 \\
(328, \\
945)\end{array}$ & 0.68 & 0.74 \\
\hline $07 / 08$ & $\begin{array}{l}0.42 \\
(0.2, \\
0.55)\end{array}$ & $\begin{array}{r}0.026 \\
(0.01,0.06)\end{array}$ & $\begin{array}{r}0.66 \\
(0.31, \\
0.79)\end{array}$ & $\begin{array}{c}0.078 \\
(0.04 \\
0.09)\end{array}$ & $\begin{array}{r}0.37 \\
(0.13 \\
0.53)\end{array}$ & $\begin{array}{r}908 \\
(794, \\
989)\end{array}$ & $\begin{array}{r}32(9, \\
56)\end{array}$ & $\begin{array}{r}620 \\
(370, \\
926)\end{array}$ & 0.68 & 0.87 \\
\hline 08/09 & $\begin{array}{r}0.41 \\
(0.27 \\
0.54)\end{array}$ & $\begin{array}{r}0.087 \\
(0.07,0.09)\end{array}$ & $\begin{array}{r}0.47 \\
(0.21, \\
0.68)\end{array}$ & $\begin{array}{r}0.096 \\
(0.05,0.1)\end{array}$ & $\begin{array}{r}0.71 \\
(0.39, \\
0.83)\end{array}$ & $\begin{array}{r}859 \\
(580, \\
978)\end{array}$ & $\begin{array}{r}102(39, \\
174)\end{array}$ & $\begin{array}{r}976 \\
(745, \\
999)\end{array}$ & 0.50 & 0.77 \\
\hline
\end{tabular}

29 
2

31 Table 3: Storage totals (S) are given for the annual means of the individual calibration 32 periods in the context of mean annual transit times (TT). Note that $S_{u p}$ is only given for 33 values exceeding the baseline when lateral and vertical fluxes were generated from this 34 reservoir.

\begin{tabular}{|l|c|c|c|c|c|c|c|c|c|}
\hline $\begin{array}{l}\text { Calibration } \\
\text { period }\end{array}$ & $\mathbf{S}_{\text {up }}$ & $\mathbf{S}_{\text {sat }}$ & $\mathbf{S}_{\text {low }}$ & $\mathbf{M V}_{\text {up }}$ & $\mathbf{M V}_{\text {sat }}$ & lowS $_{\mathbf{p}}$ & $\mathbf{S}$ & $\mathbf{Q}$ & $\mathbf{T}$ \\
\hline Units & $\mathrm{mm}$ & $\mathrm{mm}$ & $\mathrm{mm}$ & $\mathrm{mm}$ & $\mathrm{mm}$ & $\mathrm{mm}$ & $\left(\mathrm{mm} \mathrm{yr}^{-1}\right)$ & $\left(\mathrm{mm} \mathrm{yr}^{-1}\right)$ & $\mathrm{yr}$ \\
\hline $03 / 04$ & 3.2 & 5.3 & 5.7 & 33.1 & 7.2 & 878 & 933 & 435 & 2.14 \\
\hline $04 / 05$ & 4.9 & 20.3 & 23.4 & 104.0 & 28.8 & 931 & 1112 & 461 & 2.42 \\
\hline $05 / 06$ & 5.7 & 14.2 & 72.4 & 93.7 & 46.2 & 742 & 974 & 466 & 2.09 \\
\hline $06 / 07$ & 10.3 & 26.9 & 133.0 & 24.5 & 33.5 & 768 & 996 & 740 & 1.35 \\
\hline $07 / 08$ & 4.8 & 18.7 & 64.6 & 447.1 & 32.2 & 620 & 1187 & 593 & 2.00 \\
\hline $08 / 09$ & 8.6 & 5.8 & 37.6 & 92.8 & 16.5 & 976 & 1137 & 485 & 2.35 \\
\hline
\end{tabular}




1
2
3 $\quad 35$

4

5

6

7

10

11

12

13

14

15

16

17

18

19

20

21

22

23

24

25

26

27

28

29

30

31

32

33

34

35

36

37

38

39

40

41

42

43

44

45

46

47

48

49

50

51

52

53

54

55

56

57

58

59

60

http://mc.manuscriptcentral.com/hyp 


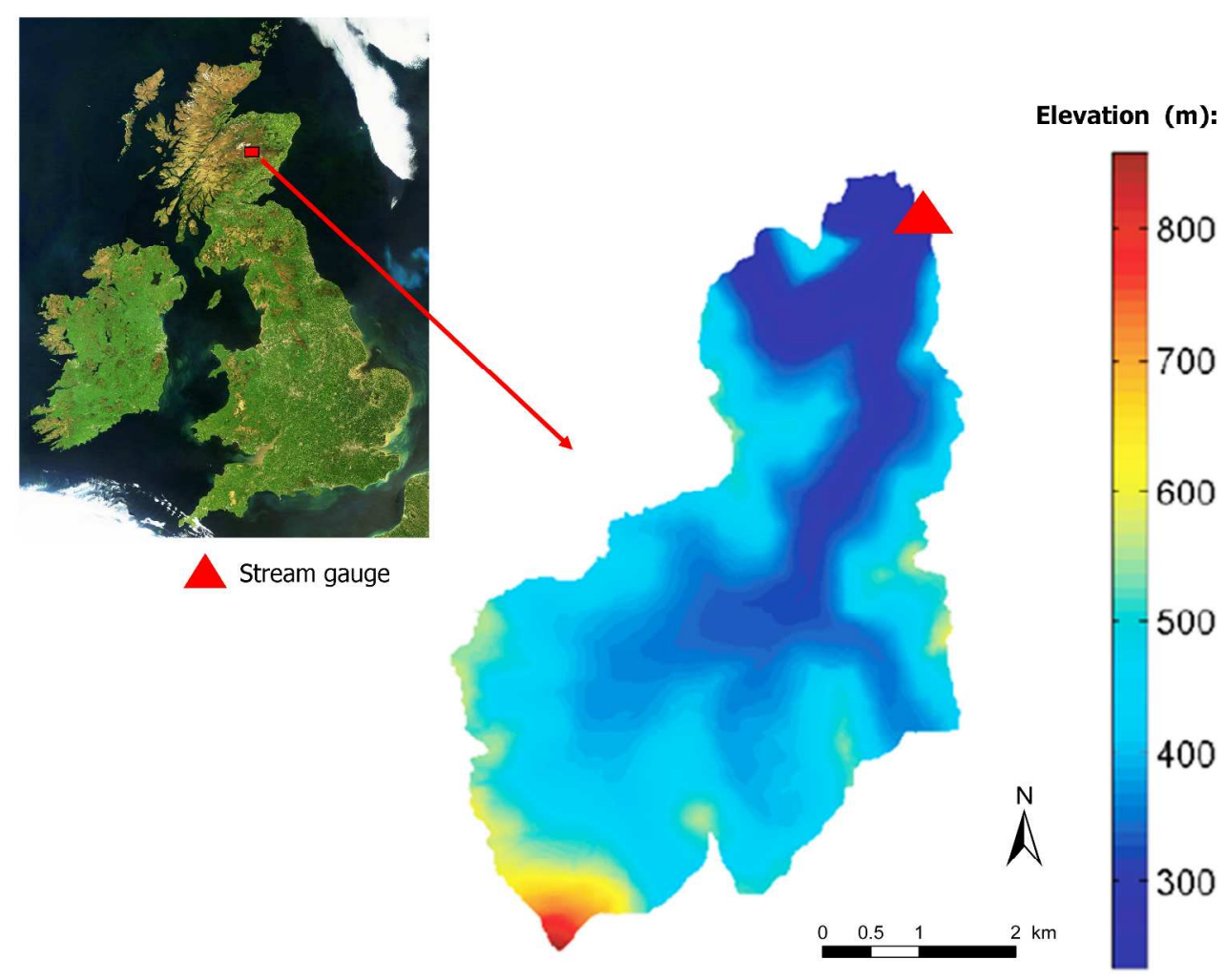

Figure 1: Location and topography of the Girnock experimental catchment. $287 \times 226 \mathrm{~mm}(300 \times 300 \mathrm{DPI})$ 
Figure 2: The model concept used to simulate discharge and oxygen-18. Three reservoirs (upper, lower and saturation area) conceptualize water and tracer fluxes with associated dynamic storage (Sup, Slow and Ssat) and additional storage available for mixing (upSp, lowSp and satSp). The latter calibrated additional storage parameters are converted into dynamic mixing volumes MV according to wetness state (dSAT) assuming that during expansion of the saturation areas (> wetness) more additional storage is available for mixing contrary to the hillslopes. Note that calibrated parameters are shown in red.

\section{$249 \times 177 \mathrm{~mm}(300 \times 300 \mathrm{DPI})$}



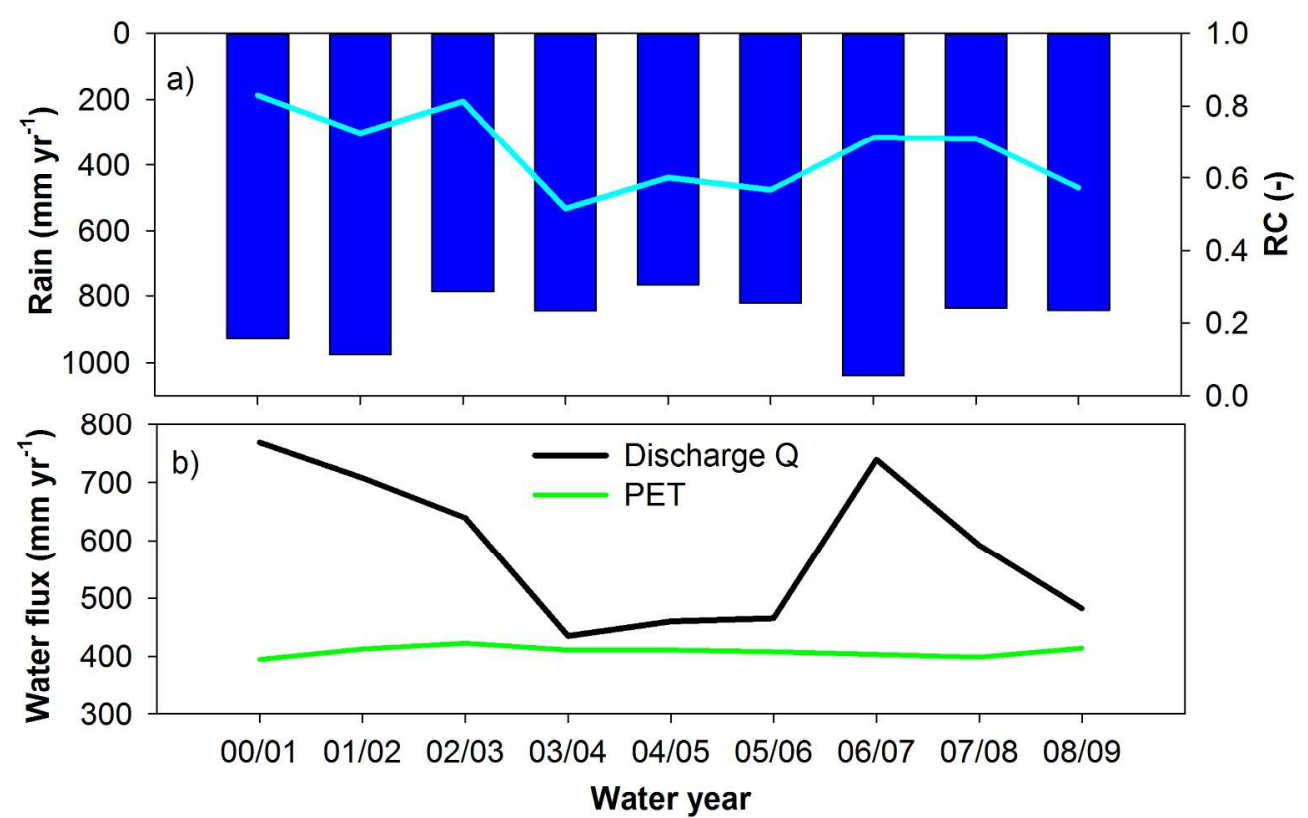

Figure 3: Mean annual water balance ( $P, Q$ and PET) and runoff coefficients (RC) emphasize the climate variability in form of the drought period 2003. $201 \times 128 \mathrm{~mm}(300 \times 300 \mathrm{DPI})$ 
Figure 4: Discharge and isotope simulations are plotted using the range of the individual calibration periods. The simulation ranges were derived from the best parameter population ( 500 sets) of each calibration window (shown as Pareto fronts in Figure 5 with parameter ranges given in Table 2). Simulation bounds indicate parameter variability as a proxy for uncertainty. Note that the same colour code is used throughout and that discharge is plotted on a logarithmic scale. $290 \times 180 \mathrm{~mm}(300 \times 300$ DPI) 


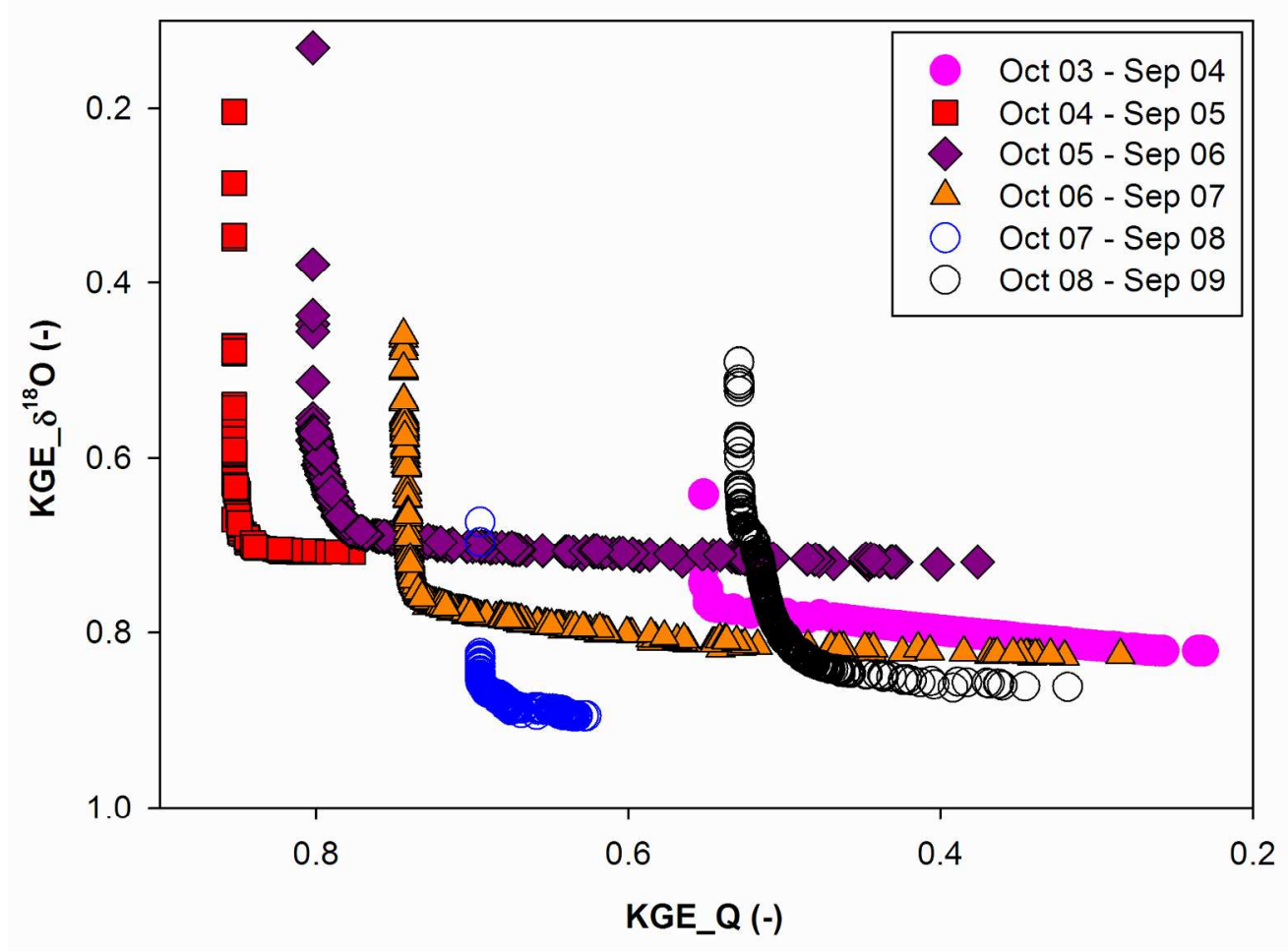

Figure 5: Pareto fronts of annual time windows (water years) derived from multi-objective calibration (NSGA2) using discharge and $\delta^{18} \mathrm{O}$ time series. Performance was assessed using the Kling-Gupta efficiency (KGE).

$188 \times 140 \mathrm{~mm}(300 \times 300 \mathrm{DPI})$ 


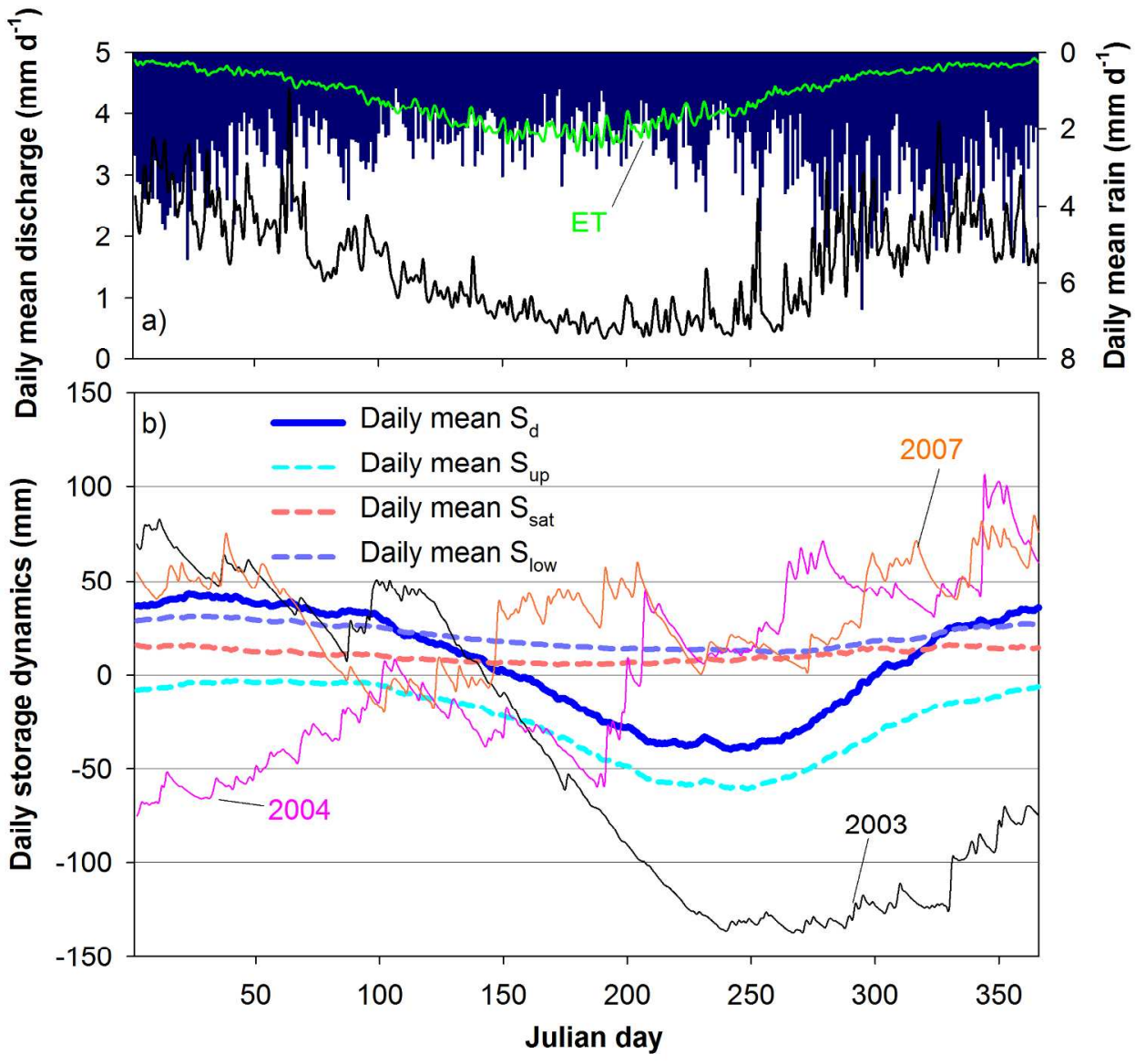

Figure 6: a) Daily mean rain (blue), discharge (black) and PET. b) Model derived mean daily dynamic storage $\left(S^{d}\right.$ - blue line), daily mean individual storages (dashed lines) and daily dynamic storage for selected years $(2003,2004$ and 2007). Note that the scale is Julian days emphasizing the carry-over effect of the drought period 2003.

$203 \times 185 \mathrm{~mm}(300 \times 300$ DPI $)$ 

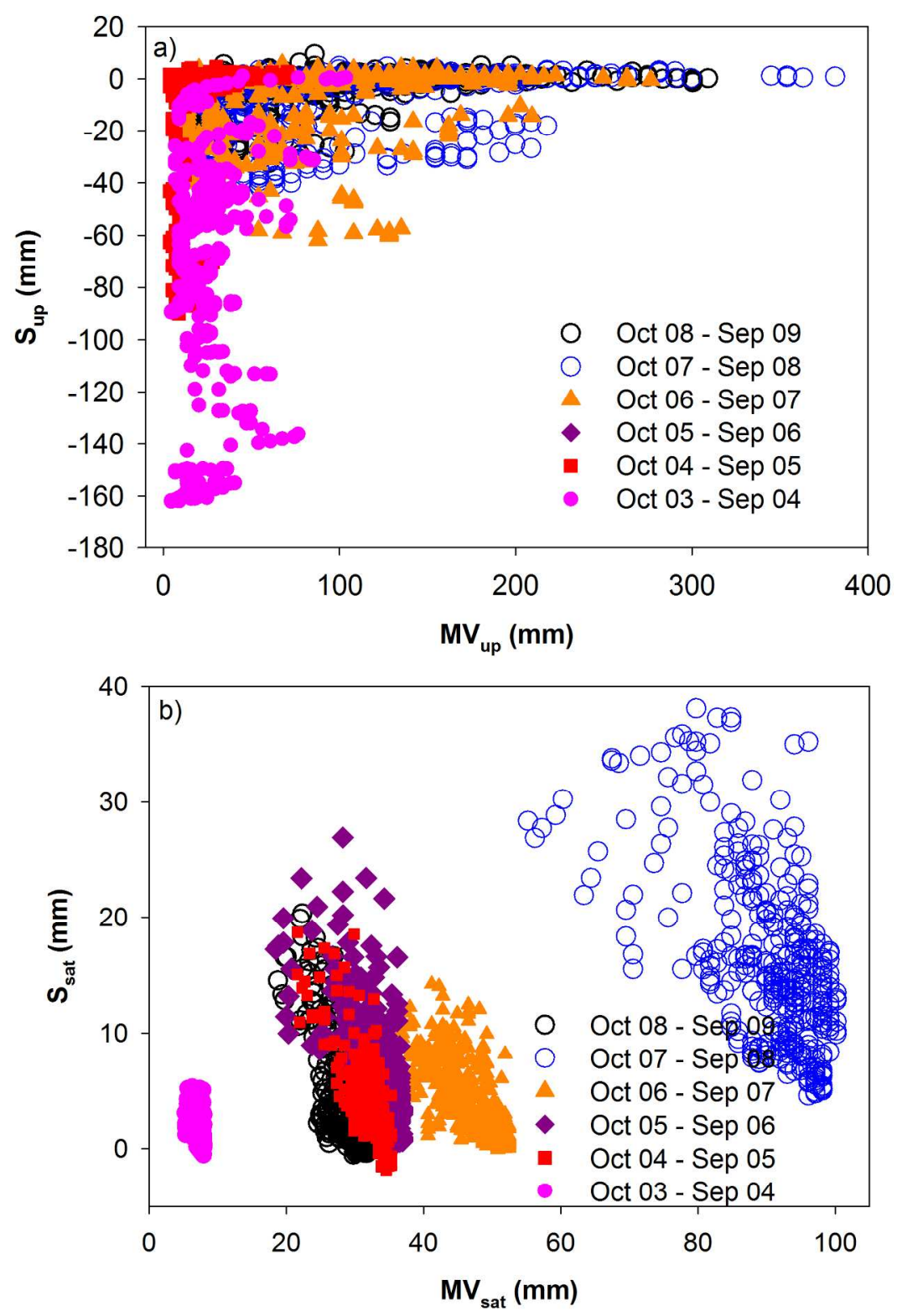

Figure 7: a) Active hillslope and b) saturation area storages are individually plotted against dynamic mixing volumes for the six complete water years spanning the study period 2003 to 2009. $164 \times 240 \mathrm{~mm}(300 \times 300$ DPI) 

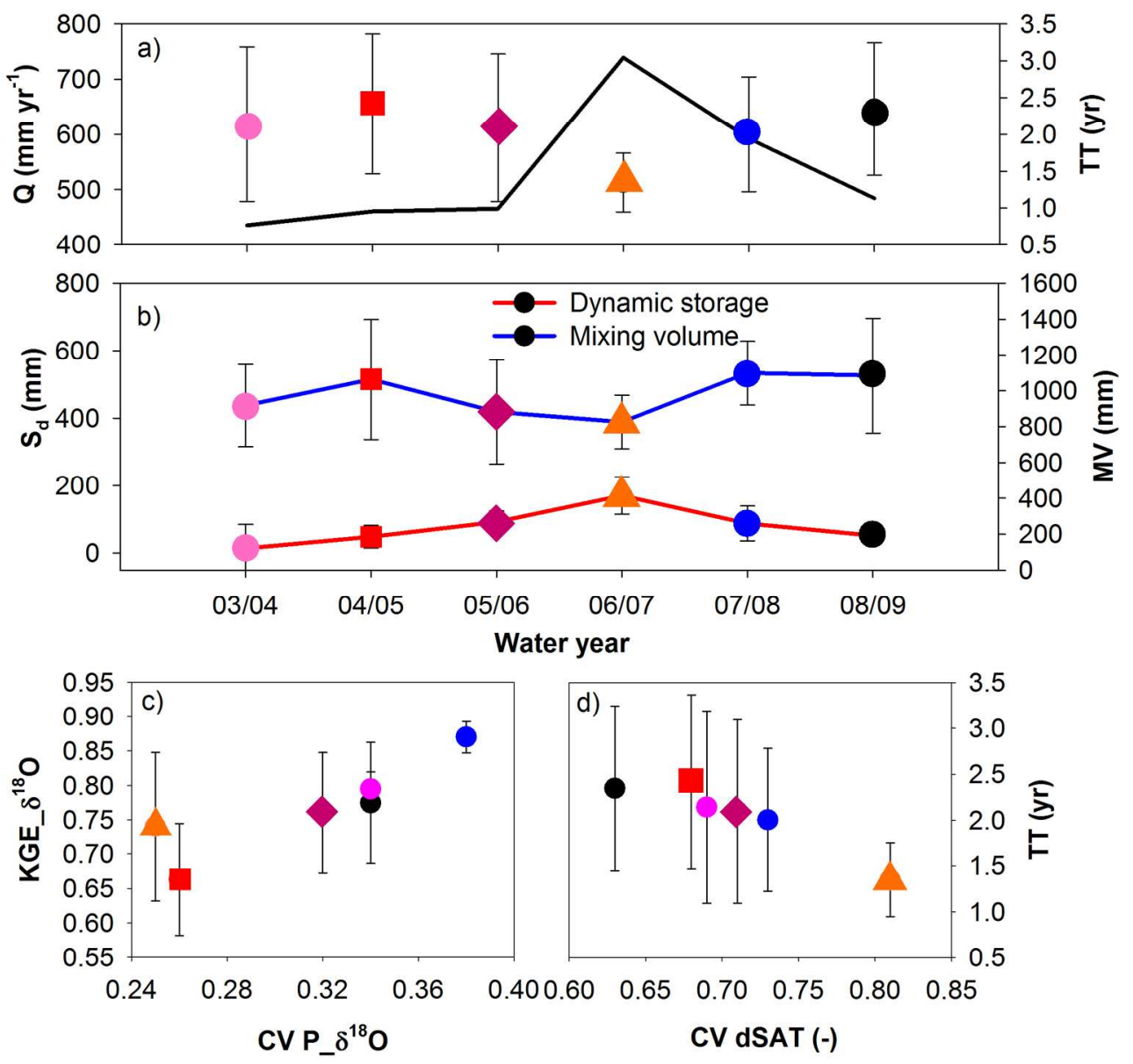

Figure 8: Annual dynamic and additional storage available for mixing (sum of three reservoirs, respectively) are shown in relation to a) mean annual discharge $Q$ and resulting mean transit time (TT) estimates. b) shows the dynamic storage against additional mixing volumes and c) show the relationship of precipitation isotope input variability (CV $\left.P_{-} \delta^{18} \mathrm{O}\right)$ to model performance (KGE) simulating stream $\delta^{18} \mathrm{O}$ and $\mathrm{d}$ ) the variability of catchment wetness (CV dSAT) to TT. Error bars reflect standard deviations across all simulations reflecting interannual variability. $209 \times 195 \mathrm{~mm}(300 \times 300 \mathrm{DPI})$ 
Figure 9: The conceptual diagram shows the main controls in terms of a) tracer damping (measured oxygen-18 input-output time series), b) near-surface flow pathways (daily histogram), c) connectivity (daily histogram) and d) dynamic storage (simulated time series) on e) streamwater age exemplified using two contrasting (dry 2004/05 in red and wet 2006/07 in orange) water years. The degree of tracer damping is highly variable on an inter-annual basis, but reflects the additional storage needed for mixing and resulting streamwater age time series and CDF (see also Figure 8 and Table 2 for mean annual average values). Note that the time series are coloured according to the previously used scheme. $451 \times 281 \mathrm{~mm}(300 \times 300 \mathrm{DPI})$ 